\title{
Epidemiological Profile of Patients with Infective Endocarditis at three Tertiary Centers in Brazil from 2003 to 2017
}

Renato Lott Bezerra, ${ }^{\circledR}$ Lucas Sousa Salgado, ${ }^{2 \oplus}$ Yago Machado da Silva, ${ }^{3 \oplus}$ Gustavo Guimarães Rocha Figueiredo, ${ }^{4}$ Raimundo Matos Bezerra Filho, ${ }^{(\circledR)}$ Eduardo Luís Guimarães Machado, ${ }^{6}{ }^{\circledR}$ Isabel Cristina Gomes, ${ }^{\circ}$ Ângelo Geraldo José Cunha² ${ }^{(0}$

Hospital João XXIII, ${ }^{1}$ Belo Horizonte, MG - Brazil

União Educacional do Vale do Aço, ${ }^{2}$ Ipatinga, MG - Brazil

Complexo de Saúde São João de Deus, ${ }^{3}$ Divinópolis, MG - Brazil

FAMINAS-BH, ${ }^{4}$ Belo Horizonte, $M G-$ Brazil

Hospital Márcio Cunha, ${ }^{5}$ Ipatinga, MG - Brazil

Hospital Santa Casa de Misericórdia de Belo Horizonte, ${ }^{6}$ Belo Horizonte, MG - Brazil

Faculdade de Ciências Médicas de Minas Gerais, ${ }^{7}$ Belo Horizonte, MG - Brazil

\section{Abstract}

Background: Infective endocarditis (IE) is a disease with high morbimortality and an increasing incidence. With improved diagnosis and treatment, a number of epidemiological changes have been reported over time.

Objectives: We sought to describe the epidemiological profile, mortality predictors, and analysis of a possible microbiological transition in patients admitted to three tertiary centers in Brazil.

Methods: In this cross-sectional retrospective study, data from 211 patients with definite or probable IE were analyzed according to the modified Duke criteria between 2003 and 2017. The association between categorical variables was assessed using the chi-square or Fisher's exact test, and binary logistic models were built to investigate mortality. We considered $\mathrm{p}<0.05$ statistically significant.

Results: The median age of the sample was 48 (33-59) years old, $70.6 \%$ were men, and the most prevalent pathogen was Staphylococcus spp. (19\%). Mortality was $22.3 \%$, with increasing age being the leading risk factor for death ( $\mathrm{p}=$ 0.028). Regarding the location of the disease, native valves were the most affected site, with the aortic valve being more affected in men than women $(p=0.017)$. The mean number of cases of Staphylococcus spp. $(\tau=0.293, p=0.148)$ and Streptococcus spp. $(\tau=-0.078, \mathrm{p}=0.727)$ has remained stable over the years.

Conclusion: No trend towards reduced or increased mortality was evident between 2003 and 2017. Although Staphylococcus spp. were the most prevalent pathogen, the expected epidemiological transition could not be observed.

Keywords: Infective Endocarditis; Epidemiology; Mortality; Streptococci; staphylococci; Hospitalization; Comorbidities.

\section{Introduction}

With improved resources for the prevention, diagnosis, and treatment of infective endocarditis (IE), significant changes in the characteristics of the disease have been reported over time. If, on the one hand, the prevalence of IE due to rheumatic valve disease has decreased, on the other, there has been an increase in IE related to degenerative valve disease in older adults, valve replacement surgery, the implantation of intracardiac devices, and the use of injectables and hemodialysis. Coincidentally, IE cases due to Staphylococcus spp. have surpassed those of Streptococcus spp., and cases due to atypical microorganisms have also increased. ${ }^{1,2}$ This microbiological change is attributed to medical progress and the resulting increase in invasive procedures.,

Despite efforts to the contrary, IE is still considered a condition with persistently high morbimortality,

Mailing Address: Lucas Salgado

Rua João Patrício, 179. Postal Code: 35164-314, Veneza, Ipatinga, MG - Brazil.

E-mail: lucasalgado1@gmail.com 
and its incidence has increased over time. ${ }^{1}$ However, most studies that observed this change were conducted in developed countries, and it is unclear whether developing countries are susceptible to this epidemiological transition to the same extent and magnitude, given the possible difference in access to medical resources. ${ }^{3}$ Furthermore, it is extremely relevant to understand the risk factors associated with mortality as well as the profile of patients affected by IE. 5,6

Only 10 epidemiological studies on IE have been published in Brazil, and none of them addressed this possible change, especially since their samples were included over a limited time span. Considering the high regional variability and epidemiological transition in IE, the purpose of this study was to survey the characteristics of a population of patients with IE over 14 years to analyze the behavior of variables over time, determine predictors of mortality, and better understand the profile of affected individuals.

\section{Methods}

\section{Sample description and design}

This observational, retrospective, cross-sectional study included 211 patients admitted to 3 tertiary health centers in Ipatinga and Belo Horizonte in the state of Minas Gerais, Brazil, between 2003 and 2017. An initial survey of medical records containing International Classification of Diseases related to IE (ICD 10 I33.0) was conducted. These records were analyzed and information on epidemiological, microbiological, valvular, and outcome characteristics were collected in an Excel database.

The inclusion criterion was definite or probable IE according to the modified Duke criteria. ${ }^{7}$ Patients whose medical records were incomplete, who were transferred during hospitalization, or who were still hospitalized at the time of analysis were excluded. After selection, data from the medical records were collected, including age, sex, blood culture, and prognosis. The microbiology was determined through blood culture results, and the location of the IE was determined through echocardiographic or perioperative findings.

This study was approved by the ethics committee of the Faculty of Medical Sciences of Minas Gerais (CAAE
60893616.7.0000.5134). Informed consent was not required due to the retrospective nature of the study.

\section{Statistical analysis}

Categorical variables are presented as absolute and relative frequencies, and quantitative variables are presented as median ( $1^{\text {st }}-3^{\text {rd }}$ quartile). The normality of quantitative variables was assessed using the ShapiroWilk test, while the Wilcoxon-Mann-Whitney test was used to compare quantitative variables among groups. The association between categorical variables was assessed using the chi-square test and Fisher's exact test. Binary logistic models were constructed to verify the association with mortality, and the results are presented as odds ratios (OR) and 95\% confidence intervals. The Mann-Kendall test was used to verify the temporal trend. The analysis was performed in $R$ version 3.5.2, with $p$ $<0.05$ considered significant.

\section{Results}

The sample consisted of 211 patients, whose profile has been described in a previous study: 110 from Belo Horizonte and 101 from Ipatinga. Their median age was 48.0 (33-59) years and 70.6\% were men. Bacteria of the genus Staphylococcus were the most prevalent pathogens, observed in $19 \%$ of cases, with Staphylococcus aureus occurring in $10 \%$ and Coagulase-negative Staphylococci in $9 \%$. Native valves were the site of IE in $70.6 \%$ of the cases, and the greatest prevalence was in the mitral valve (41.7\%), (Table 1).

\section{Mortality}

Overall mortality was $22.3 \%$. It was observed that increasing age is a risk factor for death $(p=0.028)$. However, when the sample was stratified into patients younger and older than 65 years of age, there was no statistical relevance (Table 2). Among patients younger than 65 years who died, the native aortic valve was the most affected site (33.3\%) and Staphylococcus spp. was the most frequent pathogen, representing $30.6 \%$ of the cases. Regarding the 11 deaths in patients older than 65 years, most were due to Streptococcus spp., and the most prevalent location was the native mitral valve. Sex, blood culture findings, and lesion location had no statistical relevance on mortality. Mortality from IE remained stable between 2003 and $2017(\tau=0.010)$. The highest and lowest death rates occurred in 2004 and 2012, respectively. 
Table 1 - Characteristics of 211 patients with infective endocarditis

$\begin{array}{lc}\text { Characteristic } & \text { Total } \\ (n=211)\end{array}$

Sex

Male

$149(70.6 \%)$

Female

$62(29.4 \%)$

Age (years) (median $\left[1^{\text {st }}-3^{\text {rd }}\right.$ quartile])

$48.00(33-59)$

$<18$

$15(7.1 \%)$

18 to 29

$25(11.8 \%)$

30 to 44

$55(26.1 \%)$

45 to 64

$78(37 \%)$

65 or more

$38(18 \%)$

Definite infective endocarditis*

$118(56 \%)$

Possible infective endocarditis*

Deaths

$47(22.3 \%)$

Blood culture findings

Staphylococcus spp.

$40(19 \%)$

Staphylococcus aureus

$21(10 \%)$

Coagulase-negative Staphylococci

$19(9 \%)$

Streptococcus spp.

$31(14.7 \%)$

Enterococcus spp.

$14(6.6 \%)$

Other†

$10(4.7 \%)$

Not specified

$14(6.6 \%)$

Negative blood culture

$71(33.6 \%)$

Location

Native valvesł

$149(70.6 \%)$

Mitral

$88(41.7 \%)$

Aortic

$56(26.5 \%)$

Tricuspid

$21(10 \%)$

Pulmonary

$3(1.4 \%)$

Prosthetic valves

$51(24.2 \%)$

Pacemaker cable

Other§

Unidentified location

* According to the modified Duke criteria for infective endocarditis?.

+ Candida spp., Proteus mirabilis, Proteus penneri, E. coli, Enterobacter sp., Klebsiella sp., Achromobacter xylosoxidans, Morganella morganii,

Stenotrophomonas maltophilia, Facklamia hominis.

‡ Some patients had lesions in more than one place.

$\S$ Right atrium, pulmonary arteries, ostium of the interventricular defect, ostium of the superior vena cava. 
Table 2 - Mortality risk analysis in $\mathbf{2 1 1}$ patients with infective endocarditis

\begin{tabular}{|c|c|c|c|c|}
\hline \multirow[b]{2}{*}{ Characteristic } & \multicolumn{2}{|c|}{ Death } & \multirow[b]{2}{*}{ OR (CI 95\%) } & \multirow[b]{2}{*}{ p-value } \\
\hline & $\begin{array}{c}\text { No } \\
(n=164)\end{array}$ & $\begin{array}{c}\text { Yes } \\
(n=47)\end{array}$ & & \\
\hline \multicolumn{5}{|l|}{ Sex } \\
\hline Male & $117(71.3 \%)$ & $32(68.1 \%)$ & - & - \\
\hline Female & $47(28.7 \%)$ & $15(31.9 \%)$ & $1.167(0.568 ; 2.323)$ & 0.611 \\
\hline Age (years) (median [ $1^{\text {st }}-3^{\text {rd }}$ quartile]) & $46.00(31-59)$ & $52.00(39-63)$ & $1.020(1.003 ; 1.039)$ & 0.028 \\
\hline$<65$ & $137(83.5 \%)$ & $36(76.6 \%)$ & - & - \\
\hline 65 or more & $27(16.5 \%)$ & $11(23.4 \%)$ & $1.550(0.263 ; 3.358)$ & 0.277 \\
\hline \multicolumn{5}{|l|}{ Blood culture findings } \\
\hline Staphylococcus spp. & $28(17.1 \%)$ & $12(25.5 \%)$ & $1.665(0.750 ; 3.548)$ & 0.195 \\
\hline Staphylococcus aureus & $15(9.1 \%)$ & $6(12.8 \%)$ & $1.454(0.493 ; 3.827)$ & 0.467 \\
\hline Coagulase-negative Staphylococci & $13(7.9 \%)$ & $6(12.8 \%)$ & $1.700(0.568 ; 4.590)$ & 0.311 \\
\hline Streptococcus spp. & $26(15.9 \%)$ & $5(10.6 \%)$ & $0.632(0.204 ; 1.625)$ & 0.377 \\
\hline Enterococcus spp. & $9(5.5 \%)$ & $5(10.6 \%)$ & $2.050(0.603 ; 6.268)$ & 0.219 \\
\hline Other ${ }^{*}$ & $10(6.1 \%)$ & - & - & - \\
\hline Not specified & $11(6.7 \%)$ & $3(6.4 \%)$ & $0.948(0.208 ; 3.197)$ & 0.937 \\
\hline Negative blood culture & $59(36 \%)$ & $12(25.5 \%)$ & $0.610(0.285 ; 1.237)$ & 0.184 \\
\hline \multicolumn{5}{|l|}{ Location } \\
\hline Native valves $\dagger$ & $114(69.5 \%)$ & $35(74.5 \%)$ & $1.279(0.627 ; 2.756)$ & 0.511 \\
\hline Mitral & $70(42.7 \%)$ & $18(38.3 \%)$ & $0.833(0.423 ; 1.609)$ & 0.591 \\
\hline Aortic & $43(26.2 \%)$ & $13(27.7 \%)$ & $1.076(0.506 ; 2.190)$ & 0.844 \\
\hline Tricuspid & $15(9.1 \%)$ & $6(12.8 \%)$ & $1.454(0.493 ; 3.827)$ & 0.467 \\
\hline Pulmonary & $2(1.2 \%)$ & $1(2.1 \%)$ & $1.761(0.081 ; 18.779)$ & 0.647 \\
\hline Prosthetic valves & $40(24.4 \%)$ & $11(23.4 \%)$ & $0.947(0.426 ; 1.985)$ & 0.889 \\
\hline Pacemaker cable & $7(4.3 \%)$ & $2(4.3 \%)$ & $0.997(0.145 ; 4.297)$ & 0.997 \\
\hline Otherf & $5(3 \%)$ & $1(2.1 \%)$ & $0.691(0.036 ; 4.428)$ & 0.739 \\
\hline Unidentified location & $3(1.8 \%)$ & - & - & - \\
\hline \multicolumn{5}{|c|}{$\begin{array}{l}\text { * Candida spp., Proteus mirabilis, Proteus penneri, E. coli, Enterobacter sp., Klebsiella sp., Achromobacter xylosoxidans, Morganella morganii, } \\
\text { Stenotrophomonas maltophilia, Facklamia hominis. OR: odds ratio. } \\
\text { t Some patients had lesions in more than one place. } \\
\neq \text { Right atrium, pulmonary arteries, ostium of the interventricular defect, ostium of superior vena cava. } \\
\text { P-value refers to the logistic regression model. }\end{array}$} \\
\hline
\end{tabular}

\section{Differences between the sexes}

Of the 211 patients, 149 were men and 62 were women. A total of $82.3 \%$ of the men and $81.9 \%$ of the women diagnosed with IE were younger than 65 years of age (no significant difference). Native valves were most affected, especially the mitral valve, regardless of the patient's sex, representing $40.3 \%$ of the infections in men and $45.2 \%$ in women, while the pulmonary valve was the least affected site. Of note, prosthetic valve endocarditis occurred in $22.8 \%$ and $27.4 \%$ of the men and women, respectively, at a ratio of approximately 
1:3 in relation to native valves. The native aortic valve was significantly more affected in men than women $(p=0.017)$. There was no association between the other findings (blood culture, age group, and other IE sites) and sex.

\section{Microbiological agent}

Table 3 shows the relationship between microbiological findings, age, and affected valve. There was no association between a specific microorganism and age, with individuals younger or older than 65 being equally affected. Infection by atypical microorganisms was more common in patients with prosthetic valve endocarditis $(p=0.014)$. Individuals without mitral lesions were more prone to infection by Coagulase-negative Staphylococci $(\mathrm{p}=$ 0.026). Regarding the main pathogens found during the study period (Figure 1), all had a non-significant trend according to the Mann Kendall test: Staphylococcus spp. $(\tau$ $=0.293, \mathrm{p}=0.148)$, Streptococcus spp. $(\tau=-0.078, \mathrm{p}=0.727)$ and negative blood culture $(\tau=-0.332, p=0.100)$, which indicates that the occurrence of these microorganisms was stable over the years.

\section{Discussion}

IE is a serious infectious disease, and a multidisciplinary approach involving specialists is necessary to treat and monitor these patients. Although the incidence of IE has been increasing over the years, ${ }^{9}$ few studies have been published on IE in developing countries, which makes a general analysis difficult. The overall mortality in our sample was $22.3 \%$, which is consistent with several other observational studies, ${ }^{10,11}$ including some conducted in developing countries. ${ }^{12}$ The logistic regression model (Table 2), showed that patient age was directly related to mortality [p = 0.028; OR 1.020, 95\% CI 1.003; 1.039], which agrees with other studies, eg, Khan et al., ${ }^{13}$ who obtained a similar result with a sample of 523,432 patients in the United States. Moreover, this study reported a trend over the years toward reduced mortality in IE patients, which the authors ascribed to improved medical services in the USA. However, such a trend was not observed in our analysis.

No significant differences were found regarding microbiological profile and mortality, which contrasts

Table 3 - Distribution of microbial agents according to age and location

\begin{tabular}{|c|c|c|c|c|c|c|c|c|c|}
\hline \multirow[b]{2}{*}{ Microorganism } & \multicolumn{3}{|c|}{ Age (years) } & \multicolumn{3}{|c|}{ Mitral valve affected } & \multicolumn{3}{|c|}{ Aortic valve affected } \\
\hline & $\begin{array}{c}<65 \\
n=173\end{array}$ & $\begin{array}{l}\geq 65 \\
n=38\end{array}$ & p-value & $\begin{array}{c}\text { No } \\
n=123\end{array}$ & $\begin{array}{c}\text { Yes } \\
n=88\end{array}$ & p-value & $\begin{array}{c}\text { No } \\
n=155\end{array}$ & $\begin{array}{c}\text { Yes } \\
\mathrm{n}=56\end{array}$ & $\mathrm{p}$-value \\
\hline Staphylococcus spp. & $\begin{array}{c}32 \\
(18.5 \%)\end{array}$ & $8(21.1 \%)$ & $0.892+$ & $\begin{array}{c}29 \\
(23.6 \%)\end{array}$ & $\begin{array}{c}11 \\
(12.5 \%)\end{array}$ & $0.065+$ & $\begin{array}{c}29 \\
(18.7 \%)\end{array}$ & $\begin{array}{c}11 \\
(19.6 \%)\end{array}$ & $1.000+$ \\
\hline $\begin{array}{l}\text { Staphylococcus } \\
\text { aureus }\end{array}$ & $\begin{array}{c}18 \\
(10.4 \%)\end{array}$ & $\begin{array}{c}3 \\
(7.9 \%)\end{array}$ & $0.773 \ddagger$ & $\begin{array}{c}13 \\
(10.6 \%)\end{array}$ & $\begin{array}{c}8 \\
(9.1 \%)\end{array}$ & $0.904+$ & $\begin{array}{c}18 \\
(11.6 \%)\end{array}$ & $\begin{array}{c}3 \\
(5.4 \%)\end{array}$ & $0.296 \neq$ \\
\hline $\begin{array}{l}\text { Coagulase-negative } \\
\text { Staphylococci }\end{array}$ & $14(8.1 \%)$ & $5(13.2 \%)$ & $0.348 \ddagger$ & $16(13 \%)$ & $\begin{array}{c}3 \\
(3.4 \%)\end{array}$ & $0.026 \neq$ & $11(7.1 \%)$ & $8(14.3 \%)$ & $0.181 \dagger$ \\
\hline Streptococcus spp. & $\begin{array}{c}25 \\
(14.5 \%)\end{array}$ & $6(15.8 \%)$ & $1.000+$ & $\begin{array}{c}18 \\
(14.6 \%)\end{array}$ & $\begin{array}{c}13 \\
(14.8 \%)\end{array}$ & $1.000+$ & $\begin{array}{c}22 \\
(14.2 \%)\end{array}$ & $9(16.1 \%)$ & $0.905+$ \\
\hline Enterococcus spp. & $10(5.8 \%)$ & $4(10.5 \%)$ & $0.286 \neq$ & $\begin{array}{c}7 \\
(5.7 \%)\end{array}$ & $\begin{array}{c}7 \\
(8 \%)\end{array}$ & $0.581 \ddagger$ & $\begin{array}{c}9 \\
(5.8 \%)\end{array}$ & $\begin{array}{c}5 \\
(8.9 \%)\end{array}$ & $0.531 \ddagger$ \\
\hline Other* & $\begin{array}{c}7 \\
(4 \%)\end{array}$ & $\begin{array}{c}3 \\
(7.9 \%)\end{array}$ & $0.391 \ddagger$ & $\begin{array}{c}8 \\
(6.5 \%)\end{array}$ & $\begin{array}{c}2 \\
(2.3 \%)\end{array}$ & $0.199 \ddagger$ & $\begin{array}{c}8 \\
(5.2 \%)\end{array}$ & $\begin{array}{c}2 \\
(3.6 \%)\end{array}$ & $1.000 \ddagger$ \\
\hline Not specified & $10(5.8 \%)$ & $4(10.5 \%)$ & $0.286 \ddagger$ & $10(8.1 \%)$ & $\begin{array}{c}4 \\
(4.5 \%)\end{array}$ & $0.404 \ddagger$ & $\begin{array}{c}9 \\
(5.8 \%)\end{array}$ & $\begin{array}{c}5 \\
(8.9 \%)\end{array}$ & $0.531 \ddagger$ \\
\hline $\begin{array}{l}\text { Negative blood } \\
\text { culture }\end{array}$ & $\begin{array}{c}61 \\
(35.3 \%)\end{array}$ & $\begin{array}{c}10 \\
(26.3 \%)\end{array}$ & $0.386+$ & $\begin{array}{c}35 \\
(28.5 \%)\end{array}$ & $\begin{array}{c}36 \\
(40.9 \%)\end{array}$ & $0.082+$ & $\begin{array}{c}53 \\
(34.2 \%)\end{array}$ & $\begin{array}{c}18 \\
(32.1 \%)\end{array}$ & $0.910+$ \\
\hline
\end{tabular}




\section{Table 3 (continuation) - Distribution of microbial agents according to age and location}

\begin{tabular}{|c|c|c|c|c|c|c|}
\hline \multirow{2}{*}{ Microorganism } & \multicolumn{3}{|c|}{ Tricuspid valve affected } & \multicolumn{3}{|c|}{ Prosthetic valves affected } \\
\hline & $\begin{array}{c}\text { No } \\
\mathrm{n}=190\end{array}$ & $\begin{array}{c}\text { Yes } \\
n=21\end{array}$ & p-value & $\begin{array}{c}\text { No } \\
n=160\end{array}$ & $\begin{array}{c}\text { Yes } \\
n=51\end{array}$ & p-value \\
\hline Staphylococcus spp. & $\begin{array}{c}33 \\
(17.4 \%)\end{array}$ & $\begin{array}{c}7 \\
(33.3 \%)\end{array}$ & $0.139+$ & $\begin{array}{c}31 \\
(19.4 \%)\end{array}$ & $\begin{array}{c}9 \\
(17.6 \%)\end{array}$ & $0.945+$ \\
\hline $\begin{array}{l}\text { Staphylococcus } \\
\text { Aureus }\end{array}$ & $\begin{array}{c}17 \\
(8.9 \%)\end{array}$ & $\begin{array}{c}4 \\
(19 \%)\end{array}$ & $0.140 \ddagger$ & $\begin{array}{c}17 \\
(10.6 \%)\end{array}$ & $\begin{array}{c}4 \\
(7.8 \%)\end{array}$ & $0.789+$ \\
\hline Coagulase-negative Staphylococci & $\begin{array}{c}16 \\
(8.4 \%)\end{array}$ & $\begin{array}{c}3 \\
(14.3 \%)\end{array}$ & $0.413 \ddagger$ & $\begin{array}{c}14 \\
(8.8 \%)\end{array}$ & $\begin{array}{c}5 \\
(9.8 \%)\end{array}$ & $0.784 \ddagger$ \\
\hline Streptococcus spp. & $\begin{array}{c}29 \\
(15.3 \%)\end{array}$ & $\begin{array}{c}2 \\
(9.5 \%)\end{array}$ & $0.746 \ddagger$ & $\begin{array}{c}25 \\
(15.6 \%)\end{array}$ & $\begin{array}{c}6 \\
(11.8 \%)\end{array}$ & $0.652 \dagger$ \\
\hline Enterococcus spp. & $\begin{array}{c}12 \\
(6.3 \%)\end{array}$ & $\begin{array}{c}2 \\
(9.5 \%)\end{array}$ & $0.636 \ddagger$ & $\begin{array}{c}10 \\
(6.2 \%)\end{array}$ & $\begin{array}{c}4 \\
(7.8 \%)\end{array}$ & $0.748 \ddagger$ \\
\hline Other ${ }^{*}$ & $\begin{array}{c}10 \\
(5.3 \%)\end{array}$ & - & - & $\begin{array}{c}4 \\
(2.5 \%)\end{array}$ & $\begin{array}{c}6 \\
(11.8 \%)\end{array}$ & $0.014 \ddagger$ \\
\hline Not specified & $\begin{array}{c}13 \\
(6.8 \%)\end{array}$ & $\begin{array}{c}1 \\
(4.8 \%)\end{array}$ & $1.000 \ddagger$ & $\begin{array}{c}9 \\
(5.6 \%)\end{array}$ & $\begin{array}{c}5 \\
(9.8 \%)\end{array}$ & $0.334 \ddagger$ \\
\hline Negative blood culture & $\begin{array}{c}62 \\
(32.6 \%)\end{array}$ & $\begin{array}{c}9 \\
(42.9 \%)\end{array}$ & $0.485+$ & $\begin{array}{c}56 \\
(35 \%)\end{array}$ & $\begin{array}{c}15 \\
(29.4 \%)\end{array}$ & $0.572 \dagger$ \\
\hline $\begin{array}{l}\text { * Candida spp., Proteus mirabilis, } \\
\text { Stenotrophomonas maltophilia, } F \\
+ \text { Chi-square test. } \\
\ddagger \text { Fisher's exact test. }\end{array}$ & $\begin{array}{l}\text { s penneri, } \\
\text { a hominis }\end{array}$ & erobacte & iella $s p$ & ter $x y l$ & organe & \\
\hline
\end{tabular}

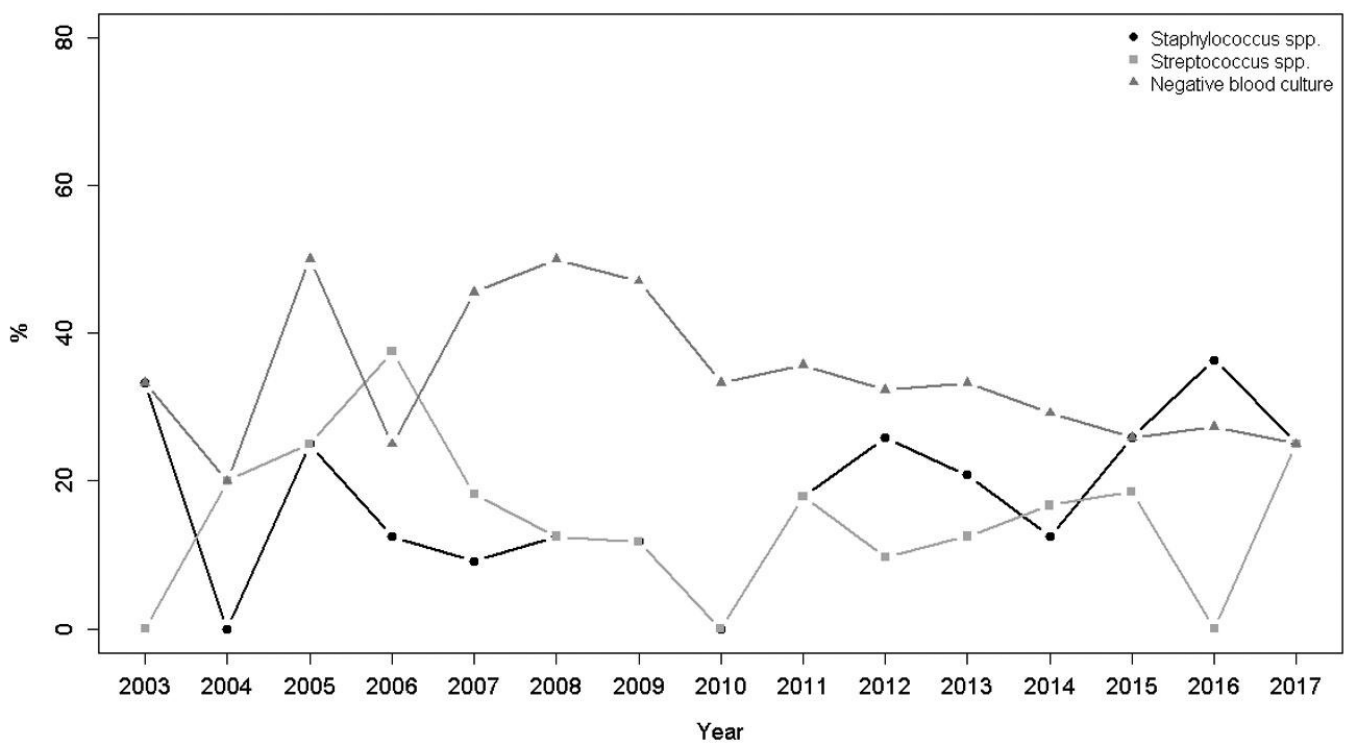

Figure 1 - Main blood culture findings per year. Figure caption: All findings had a non-significant trend according to the MannKendall test $(\tau=0.293, p=0.148$, for Staphylococcus spp.; $\tau=-0.078, p=0.727$, for Streptococcus spp. and $\tau=-0.332, p=0.100$ for blood culture negative). Source: The authors 
with the results of Joffre et al., ${ }^{14}$ who found an association between Staphylococcus spp., Candida spp. and higher in-hospital mortality, as well as an association between IE due to Streptococcus spp. and a more favorable prognosis. It should also be pointed out that these authors found male sex to be a protective factor against death. Other authors have found a direct relationship between mortality and endocarditis location, with the aortic and mitral valves having the worst outcomes. ${ }^{9,15,16}$ However, we did not observe this in the present study.

It is possible that comorbidities (e.g. hypertension, heart disease, etc.) and events (e.g. septic shock, need for surgical approach) affect prognosis more than the microbiological or valvular characteristics of the IE. Ren et al. ${ }^{15}$ found significant associations between higher mortality and conditions such as hemorrhagic and ischemic stroke, constrictive heart failure, pneumonia, and renal failure. One limitation of our study is the lack of data on these variables.

In general, IE affected men the most (70.6\%), at a ratio of 1.7:1. This difference has been found by other authors in Belgium, ${ }^{17}$ Saudi Arabia, ${ }^{18}$ and Brazil,${ }^{9,19}$ and Bakir et al., ${ }^{20}$ ascribed it to the potential protective role of estrogen against endothelial injury. Other authors have reported a lower prevalence of IE in women, including a lesser likelihood of developing sepsis. ${ }^{21,22}$ Nevertheless, none of these mechanisms are fully understood. It is curious that, although IE affects fewer women, it seems to be related to higher in-hospital mortality. ${ }^{23,24}$ In fact, prognostic scales such as the EuroSCORE and the results of MartínezSellés et al., ${ }^{25}$ indicate a worse outcome among women and a greater likelihood of death.

Furthermore, our analysis showed that native aortic valves are more affected in men than women $(p=0.017)$, which was also described by Sevilla et al., ${ }^{26}$ and Elamragy et al., ${ }^{27}$ who further described that the native mitral valve was more affected in women. Regarding the microbiological profile between the sexes, the most frequent microorganism was Staphylococcus spp. $(22.6 \%$ men vs $17.4 \%$ women, $\mathrm{p}=$ $0.501)$, a result similar to other authors. ${ }^{27}$ The equally high negative blood culture rate in men and women is also of note $(32.9 \%$ and $35.5 \%$ respectively, $\mathrm{p}=$ 0.838 ), which may be explained by the indiscriminate use of antibiotics to treat any febrile disease before obtaining cultures, a common practice in Brazil. It should be pointed out that some studies have found a much higher percentage of negative blood cultures than ours, eg, in Egypt $(69.5 \%)^{27}$ and South Africa $(55.3 \%),{ }^{28}$ while others have found lower percentages, eg, in France $(9 \%)^{29}$ and the United Kingdom (12.2\%). ${ }^{30}$ Thus, it could be cautiously inferred that Brazil is somewhere in the middle of a broad spectrum, which might be associated with improvements to the Brazilian public health system, as well as new and more effective hospital protocols.

The relationship between the affected valve and the blood culture results diverges greatly among studies. What became clear in our study was that a positive blood culture for coagulase-negative staphylococci is less related to mitral valve lesion (Table 3), which was also reported by Barrau et al., ${ }^{31}$ These authors also found that Staphylococcus aureus affects the aortic valve the least. Another important result of our study was that patients with cardiac prostheses were more likely to be affected by bacteria in the "other" category, which may reflect inadequate laboratory techniques or less strict criteria for diagnosing IE. ${ }^{32,33}$

Finally, we should point out that we found Staphylococcus spp. to be the most prevalent pathogen, which agrees with the literature. ${ }^{1-4,34}$ However, we did not observe the reported epidemiological transition toward more cases due to Staphylococcus spp. and fewer cases due to Streptococcus spp. (Figure 1) over the years as consequence of medical progress. Most studies reporting this trend have been conducted in developed countries, ${ }^{1}$ and little evidence for such a trend has been found in low/middle income countries, either due to the precariousness of medical systems or the scarcity of new studies.

\section{Limitations}

Our study is not without limitations. First, since we performed a retrospective analysis, associations between variables do not necessarily indicate a causal relationship. Second, the sample can be considered small, since we dealt with cases over 15 years at three different centers, as well as the fact that it included many probable IE cases (93 out of 211). However, few studies have been published on the epidemiological profile of Brazilian patients and, to the best of our knowledge, our study involves the largest such sample. It should also be pointed out that most of the probable IE cases involved a negative blood culture, which is related to the use of antibiotics. Third, no data 
on comorbidity, heart valve disorder, hemodynamic variables, heart failure, abscess formation, or heart valve surgery were collected. Thus, any discussion of mortality must be extremely limited. Finally, it was not possible to collect blood samples for blood culture in 34 patients, either because they received treatment prior to collection or because they began antibiotic therapy before being transferred to tertiary centers.

\section{Conclusion}

In conclusion, among the 211 IE cases included in this study, age had the greatest influence on mortality. However, a trend towards reduced or increased mortality was not evident during the study period. Although more infections occurred in native aortic valves in men than women, no specific bacteria stood out. Additionally, in patients whose IE was due to coagulase-negative staphylococci, the mitral valve was less likely to be affected, whereas patients with heart prostheses were more likely to be infected with bacteria in the "other" category. Even though Staphylococcus spp. were the most prevalent pathogen in the sample, we did not observe the epidemiological transition described in literature. Finally, further research is needed to better understand the risk factors associated with mortality in developing countries, especially comorbidities, symptoms present at admission, and the effects of surgical interventions.

\section{References}

1. Prendergast BD. The changing face of infective endocarditis. Heart. 2006;92(7):879-85.

2. Cresti A, Chiavarelli M, Scalese M, Nencioni C, Valentini S, Guerrini F, et al. Epidemiological and mortality trends in infective endocarditis, a 17-year population-based prospective study. Cardiovasc Diagn Ther. 2017;7(1):27-35.

3. Sunil M, Hieu HQ, Arjan Singh RS, Ponnampalavanar S, Siew KSW, Loch A. Evolving trends in infective endocarditis in a developing country: a consequence of medical progress? Ann Clin Microbiol Antimicrob. 2019;18(1):43.

4. Fowler VG Jr, Miro JM, Hoen B, Cabell CH, Abrutyn E, Rubinstein E, et al. Staphylococcus aureus Endocarditis: A Consequence of Medical Progress. JAMA. 2005;293(24):3012-3021.

5. Watt G, Pachirat O, Baggett HC, Maloney SA, Lulitanond V, Raoult $D$, et al. Infective endocarditis in northeastern Thailand. Emerg Infect Dis. 2014;20(3):473-6.

6. Bin Abdulhak AA, Baddour LM, Erwin PJ, Hoen B, Chu VH, Mensah GA, et al. Global and regional burden of infective endocarditis, 1990-2010: a systematic review of the literature. Glob Heart. 2014;9(1):131-143.

7. Li JS, Sexton DJ, Mick N, Nettles R, Fowler VG Jr, Ryan T, et al. Proposed modifications to the Duke criteria for the diagnosis of infective endocarditis. Clin Infect Dis. 2000;30(4):633-8.

\section{Potential Conflict of Interest}

No potential conflict of interest relevant to this article was reported.

\section{Sources of Funding}

There were no external funding sources for this study.

\section{Study Association}

This study is not associated with any thesis or dissertation work.

\section{Author contributions}

Conception and design of the research: Bezerra RL, Salgado LS, Silva YM, Figueiredo GGR, Cunha AGJ. Acquisition of data: Bezerra RL, Silva YM. Analysis and interpretation of the data: Bezerra RL, Salgado LS, Silva YM, Figueiredo GGR, Cunha AGJ. Statistical analysis: Gomes IC. Writing of the manuscript: Bezerra RL, Salgado LS, Silva YM, Figueiredo GGR. Supervision: Filho RMB, Machado ELG, Cunha AGJ. Critical revision of the manuscript for intellectual content: Filho RMB, Machado ELG, Cunha AGJ.

\section{Ethics approval and consent to participate}

This article does not contain any studies with human participants or animals performed by any of the authors.

8. Bezerra RL, Carvalho TF, Batista RS, Silva YM, Campos BF, Castro JHM, et al. Association between Insulin use and Infective Endocarditis: An Observational Study. Int J Cardiovasc Sci. 2019;33(1):14-21.

9. Damasco PV, Correal JCD, Cruz-Campos ACD, Wajsbrot BR, Cunha RGD, Fonseca AGD, et al. Epidemiological and clinical profile of infective endocarditis at a Brazilian tertiary care center: an eight-year prospective study. Rev Soc Bras Med Trop. 2019;52:e2018375.

10. Murdoch DR, Corey GR, Hoen B, Miró JM, Fowler VG Jr, Bayer AS, et al. Clinical presentation, etiology, and outcome of infective endocarditis in the 21st century: The International Collaboration on EndocarditisProspective Cohort Study. Arch Intern Med. 2009;169(5):463-73.

11. Wang A, Athan E, Pappas PA, Fowler VG Jr, Olaison L, Paré C, et al. Contemporary clinical profile and outcome of prosthetic valve endocarditis. JAMA. 2007;297(12):1354-61.

12. Ferreiros E, Nacinovich F, Casabé JH, Modenesi JC, Swieszkowski S, Cortes C, et al. Epidemiologic, clinical, and microbiologic profile of infective endocarditis in Argentina: a national survey. The Endocarditis Infecciosa en la República Argentina-2 (EIRA-2) Study. Am Heart J. 2006;151(2):545-52.

13. Khan A, Aslam A, Satti KN, Ashiq S. Infective endocarditis posttranscatheter aortic valve implantation (TAVI), microbiological profile and clinical outcomes: A systematic review. PLoS One. 2020;15(1):e0225077. 
14. Joffre J, Dumas G, Aegerter P, Dubée V, Bigé N, Preda G, et al. Epidemiology of infective endocarditis in French intensive care units over the 1997-2014 period-from CUB-Réa Network. Crit Care. 2019;23(1):143.

15. Ren Z, Mo X, Chen H, Peng J. A changing profile of infective endocarditis at a tertiary hospital in China: a retrospective study from 2001 to 2018. BMC Infect Dis. 2019;19(1):945.

16. Mistiaen WP. What are the main predictors of in-hospital mortality in patients with infective endocarditis: a review. Scand Cardiovasc J. 2018;52(2):58-68.

17. Yombi JC, Yuma SN, Pasquet A, Astarci P, Robert A, Rodriguez HV. Staphylococcal versus Streptococcal infective endocarditis in a tertiary hospital in Belgium: epidemiology, clinical characteristics and outcome. Acta Clin Belg. 2017;72(6):417-423.

18. Kaki R, Al-Abdullah N. Descriptive epidemiological, clinical and microbiological features of infective endocarditis at a University Hospital in Saudi Arabia. Am J Infect Dis. 2018;14(2):63-68.

19. Nunes MC, Gelape CL, Ferrari TC. Profile of infective endocarditis at a tertiary care center in Brazil during a seven-year period: prognostic factors and in-hospital outcome. Int J Infect Dis. 2010;14(5):e394-8.

20. Bakir S, Mori T, Durand J, Chen YF, Thompson JA, Oparil S. Estrogeninduced vasoprotection is estrogen receptor dependent: evidence from the balloon-injured rat carotid artery model. Circulation. 2000;101(20):2342-4.

21. Wichmann MW, Inthorn D, Andress HJ, Schildberg FW. Incidence and mortality of severe sepsis in surgical intensive care patients: the influence of patient gender on disease process and outcome. Intensive Care Med. 2000;26(2):167-72.

22. Oberholzer A, Keel M, Zellweger R, Steckholzer U, Trentz O, Ertel W. Incidence of septic complications and multiple organ failure in severely injured patients is sex specific. J Trauma. 2000;48(5):932-7.

23. Aksoy O, Meyer LT, Cabell CH, Kourany WM, Pappas PA, Sexton DJ. Gender differences in infective endocarditis: pre- and co-morbid conditions lead to different management and outcomes in female patients. Scand J Infect Dis. 2007;39(2):101-7.
24. Castillo JC, Anguita MP, Delgado M, Ruiz M, Mesa D, Romo E, et al. Clinical characteristics and prognosis of infective endocarditis in women. Rev Esp Cardiol. 2008;61(1):36-40.

25. Martínez-Sellés M, Muñoz P, Arnáiz A, Moreno M, Gálvez J, Rodríguez-Roda J, et al. Valve surgery in active infective endocarditis: a simple score to predict in-hospital prognosis. Int J Cardiol. 2014;175(1):133-7.

26. Sevilla T, Revilla A, López J, Vilacosta I, Sarriá C, Gómez I, et al. Influence of Sex on Left-Sided Infective Endocarditis. Rev Esp Cardiol. 2010;63(12):1497-500.

27. Elamragy AA, Meshaal MS, El-Kholy AA, Rizk HH. Gender differences in clinical features and complications of infective endocarditis: 11-year experience of a single institute in Egypt. Egypt Heart J. 2020;72(1):5.

28. Koegelenberg CF, Doubell AF, Orth H, Reuter H. Infective endocarditis in the Western Cape Province of South Africa: a threeyear prospective study. QJM. 2003;96(3):217-25.

29. Hoen B, Alla F, Selton-Suty C, Béguinot I, Bouvet A, Briançon S, et al Changing profile of infective endocarditis: results of a 1-year survey in France. JAMA. 2002;288(1):75-81.

30. Lamas CC, Eykyn SJ. Blood culture negative endocarditis: analysis of 63 cases presenting over 25 years. Heart. 2003;89(3):258-62.

31. Barrau K, Boulamery A, Imbert G, Casalta JP, Habib G, Messana T, et al. Causative organisms of infective endocarditis according to host status. Clin Microbiol Infect. 2004;10(4):302-8.

32. Cannady PB, Sanford JP. Negative blood cultures in infective endocarditis: a review. South Med J. 1976;69(11):1420-4.

33. Tunkell AR, Kaye D. Endocarditis with negative blood cultures. N Engl J Med. 1992;326(18):1215-7.

34. Wu Z, Chen Y, Xiao T, Niu T, Shi Q, Xiao Y. Epidemiology and risk factors of infective endocarditis in a tertiary hospital in China from 2007 to 2016. BMC Infect Dis. 2020;20(1):428. 